\title{
Trace Detection and Quantitation of Antibiotics in a South African Stream Receiving Wastewater Effluents and Municipal Dumpsite Leachates
}

\author{
Somandla Ncube ${ }^{1}$, Yannick Belo Nuapia ${ }^{2,3}$, Luke Chimuka ${ }^{2}$, Lawrence Mzukisi Madikizela ${ }^{4 *}$ \\ and Anita Etale ${ }^{2}$ \\ ${ }^{1}$ Department of Chemistry, Sefako Makgatho Health Sciences University, Medunsa, Ga-Rankuwa, South Africa, ${ }^{2}$ School of \\ Chemistry, Molecular Sciences Institute, University of the Witwatersrand, Johannesburg, South Africa, ${ }^{3}$ School of Animal, Plant, \\ and Environmental Science, Medicinal Plants, University of Witwatersrand, Johannesburg, South Africa, ${ }^{4}$ Institute for \\ Nanotechnology and Water Sustainability, College of Science, Engineering and Technology, University of South Africa, Pretoria, \\ South Africa
}

OPEN ACCESS

Edited by:

Jiangyong $\mathrm{Hu}$,

National University of Singapore,

Singapore

Reviewed by: Mohamed Hassaan, National Institute of Oceanography and Fisheries (NIOF), Egypt Isaac Dennis Amoah, Durban University of Technology, South Africa

${ }^{*}$ Correspondence: Lawrence Mzukisi Madikizela madiklm@unisa.ac.za

Specialty section:

This article was submitted to Water and Wastewater Management, a section of the journal Frontiers in Environmental Science

Received: 29 June 2021 Accepted: 16 August 2021 Published: 26 August 2021

Citation:

Ncube S, Nuapia YB, Chimuka L, Madikizela LM and Etale A (2021) Trace

Detection and Quantitation of Antibiotics in a South African Stream Receiving Wastewater Effluents and

Municipal Dumpsite Leachates.

Front. Environ. Sci. 9:733065.

doi: 10.3389/fenvs.2021.733065
One of the major concerns in the consumption of antibiotics is the discovery of antibacterial resistant genes due to prolonged exposure which makes their presence in environmental samples a priority. In this study, we screened 52 antibiotics along a South African stream polluted with wastewater effluents and municipal dumpsite leachates. Of these antibiotics, 15 were detected in the stream while 3 sulfonamides (sulfamethizole, sulfamethazine, sulfamethoxazole), a fluoroquinolone (flumequine) and a diaminopyrimidine (trimethoprim) were further quantified. The concentrations of sulfamethizole, sulfamethazine, sulfamethoxazole ranged from not detected to $0.133 \mathrm{Mg} \mathrm{L}^{-1}$, flumequine ranged from 0.222 to $0.686 \mathrm{\mu g} \mathrm{L}^{-1}$, while trimethoprim was up to $0.0618 \mu \mathrm{g} \mathrm{L}^{-1}$. The highest concentrations were recorded at the point source discharge with most antibiotics not detected further downstream. The current study has further confirmed wastewater effluents and dumpsite leachates as pathways of antibiotics into the environment. Only the persistent unsanctioned antibiotic, flumequine had its risk quotient above 0.1 making it an antibiotic of environmental concern. Multiresidue studies are still limited in Africa and the current study offers a platform for a research paradigm shift with more studies expected to emerge providing an improved overview of the release of antibiotics and other pharmaceuticals into Africa's vulnerable surface water systems.

Keywords: antibiotics, sulfamethoxazole, flumequine, wastewater, municipal dumpsite

\section{INTRODUCTION}

One of the greatest achievements in medicine was the discovery of the first antibiotic, penicillin for treatment of bacterial infections. Today, there are over 100 antibiotics belonging to different classes, all of which are designed to treat several types of bacterial infections. However, the major drawback from an efficacy point of view is the potential for development of resistant bacteria due to prolonged exposure to the antibiotics. Further, the presence of these bacteria in the environment can also result in food contamination, and interactions with other environmental constituents could alter the functioning of some natural resources. Although large amounts of antibiotics are available only 
through medical prescription, antibiotics are the most prescribed pharmaceuticals globally and a major concern remains their entry into surface water bodies.

One of the common pathways of pharmaceuticals into the environment is incorrect disposal of unused medication that makes its way into the environment through direct deposition or via municipal dumpsites. Another important pathway is through human excreta that undergoes some form of treatment prior to release into the environment (Michael et al., 2013). However, it has been reported worldwide that wastewater treatment plant (WWTP) processes do not eliminate pharmaceutical residues and as such quite a large number of pharmaceuticals including antibiotics have been detected in WWTP effluents (Liu and Wong, 2013; Ebele et al., 2017; Tran et al., 2018). From an African perspective, many communities including those in urban areas, do not have access to proper sanitation facilities leading to direct release of excreta and sewerage into surface water bodies (Madikizela et al., 2017). In addition, various other point sources of pharmaceuticals common in developing countries such as dumpsites, septic tank leakage, landfill leachates, and WWTP sludge used for fertilizer have been reported in literature (Madikizela et al., 2017; Philip et al., 2018; Patel et al., 2019). As a result, much higher concentrations of pharmaceuticals have been reported for Africa compared to Europe (Archer et al., 2017; Faleye et al., 2018; Fekadu et al., 2019; Offiong et al., 2019).

While there has been an increase in the number of studies reporting the occurrence of pharmaceuticals in surface water bodies of Africa (Madikizela et al., 2017, 2020; Faleye et al., 2018; Gwenzi and Chaukura, 2018), data on antibiotics still remains limited in Africa. Based on literature survey conducted over a 3 years period (2017-2019), pharmaceuticals were only monitored in 9 out of 54 African countries, with 7 studies performed the quantitation of antibiotics (total of 44 compounds) in different water matrices (Madikizela et al., 2020). Previous work has indicated that there are only ten antibiotics detected in water bodies from two out of the nine South African provinces (Faleye et al., 2018). Various studies have reported analysis of antibiotics in environmental aqueous samples impacted by WWTP effluents and municipal leachates across the world. However, in a few instances where antibiotic studies have been done (Kimosop et al., 2016; Ngumba et al., 2016, 2020; Faleye et al., 2018; Harrabi et al., 2018; Ngigi et al., 2020), the reported concentrations were almost always higher than those reported elsewhere in the world (Carvalho and Santos, 2016; Wang et al., 2020). This can be attributed to lack of pharmaceutical disposal and wastewater treatment protocols and policies which in-turn allows for improper disposal with no repercussion. In a few cases where they are available, there is no evidence of measures to ensure adherence. This implies that the potential human health risks and ecotoxicity effects of antibiotics to aquatic life in Africa is unknown. On the other hand, Europe has standing frameworks governing the discharge of effluents from the pharmaceutical industry, WWTPs, domestic solid waste and disposal of unused or expired medication (Patryn et al., 2011; Furlong et al., 2017; Lee and Choi, 2019).
Monitoring and health risk assessment studies are still a new niche in South Africa with most studies targeting mainly nonsteroidal anti-inflammatory drugs (Madikizela et al., 2020; Madikizela and Ncube, 2021). This also has implications for creation of databases of priority lists and compounds relevant to Africa. The current priority lists and regulations are based on what has been detected and/or prescribed in the developed countries which may not necessarily be appropriate as some pharmaceuticals not in those countries' lists maybe detected elsewhere. In this regard, more data for developing countries is needed to address the environmental risks associated with pharmaceuticals distributed in these geographical areas. A number of recent reviews have published data on lists of pharmaceuticals that have been detected in surface water sources in Africa (Madikizela et al., 2017, 2020; Faleye et al., 2018; Gwenzi and Chaukura, 2018). The general observation from these reviews is that the number and classes of pharmaceuticals targeted in each study remains limited. In South African alone, the number of antibiotics monitored recently in various studies is low, with 13 antibiotics monitored in Durban water bodies (Faleye et al., 2019), 4 in the surface waters of the Eastern Cape Province (Vumazonke et al., 2020) and 3 in water samples from the Gauteng Province (Mashile et al., 2021).

The current study has focused on targeted analysis of antibiotics and some important transformation products in effluents from a WWTP and leachates from a municipal dumpsite. The combined effluents and leachates are continuously deposited into the Klip River. The Klip River is an important river since it passes through the cultural Soweto Township, South Africa and its water is at times used by local communities for irrigation of vegetables and crops while at the same time fishing activities along the river contribute to the availability of food for some residents. Therefore, it is imperative to monitor the potential health impact due to antibiotics that may enter Klip River as part of wastewater effluents and municipal dumpsite leachates. This study is the first in South Africa to provide the initial screening of 52 antibiotics for the purposes of identifying and prioritizing pollutants relevant to South Africa. In addition, this is the first study to monitor the occurrence of antibiotics in Klip River which was followed by their quantification and health risk assessment.

\section{MATERIALS AND METHODS}

\section{Chemicals and Reagents}

High performance liquid chromatographic-grade methanol was purchased from Sigma Aldrich (Johannesburg, South Africa) while ultra-high purity water was prepared in the laboratory using Milli-QRO4 system 117 (Millipore, Bedford, MA, United States). The quantified antibiotics (sulfamethizole, sulfamethazine, sulfamethoxazole, trimethoprim and flumequine) were all analytical grade and supplied in powder form by Merck Chemicals (Pty) Ltd. (Johannesburg, South Africa). 


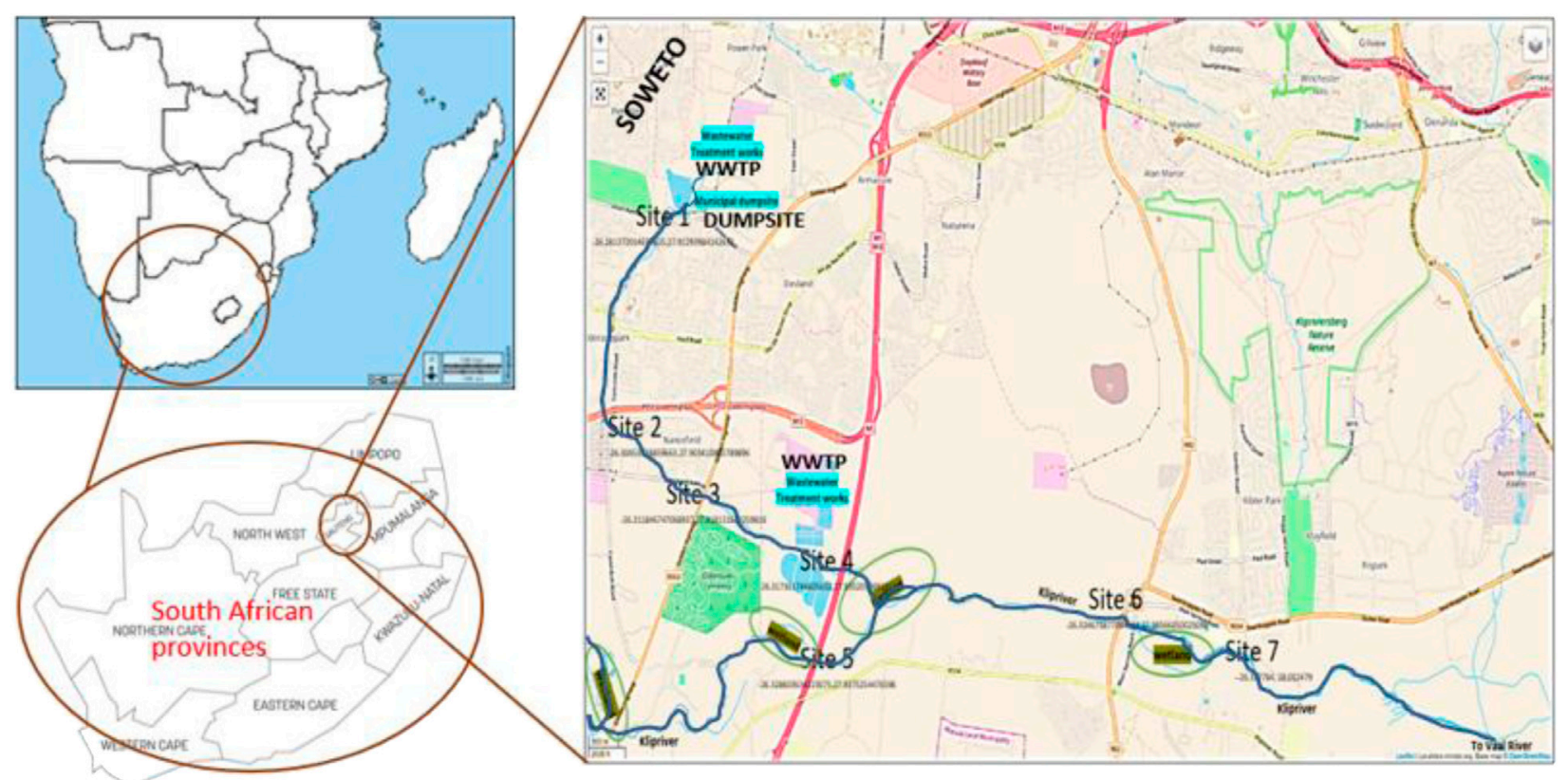

FIGURE 1 | Sampling sites.

\section{Study Site}

In this study, a stream with effluents from a WWTP and leachates from a municipal dumpsite was investigated. The WWTP and the municipal dumpsite are within $1 \mathrm{~km}$ of each other (Figure 1). The stream pours into the Klip River, whose catchment is in western side of Johannesburg city and passes through a cultural township, Soweto. The stream however enters the river after the river has passed Soweto. There is a massive wetland at the point where the stream meets with the river (Figure 1). The Klip River has various wetlands along its length artificially designed for the removal of its pollutants.

The WWTP, the municipal dumpsite and the holding dam are all in a protected area and access by external persons is not permitted. Samples were, therefore, collected as the stream exits the holding dam (Site 1), within $5 \mathrm{~km}$ of the holding dam (Site 2), within $10 \mathrm{~km}$ of the holding dam (Site 3 ) as well as where the stream meets another from a separate WWTP just before entering the Klip River (Site 4). Site 4 is within $100 \mathrm{~m}$ prior to the streamriver confluence. Another sample was collected along the Klip River within a kilometer before meeting the stream from the WWTPs and the dumpsite (Site 5). Site 6 is within $5 \mathrm{~km}$ after the Klip River has combined with the effluent stream. Further down the river is Site 7 which is within $1 \mathrm{~km}$ of Site 6 but occurs after another large artificial wetland. The choice of sampling sites was influenced by the distance between the WWTP/dumpsite and sampling site of interest as well as accessibility into the stream.

\section{Sampling and Sample Preparation}

Grab samples $(100 \mathrm{ml})$ were collected at $30 \mathrm{~min}$ intervals over a $4 \mathrm{~h}$ period during the day from morning to afternoon, filtered through 0.45-micron hydrophilic polypropylene membrane filters obtained from Pall Corporation (Michigan,
United States) and poured into the same $2 \mathrm{~L}$ brown bottle. The samples were then transported to the laboratory in cooler boxes where they were homogenized by shaking and immediately subjected to filtration for removal of suspended particles prior to solid phase extraction (SPE). The extracts of SPE were injected into the UHPLC-QTOF-MS system for analysis.

\section{Automated Solid Phase Extraction}

The automated SPE system was a Dionex ${ }^{\mathrm{TM}}$ Auto Trace $^{\mathrm{TM}} 280$ SPE from Thermo Fisher Scientific (Waltham, MA, United States). Extraction was performed using $200 \mathrm{mg}$ Oasis HLB cartridges $(6 \mathrm{cc}$ ) from Waters Corporation (Milford, MA, United States) as the sorbents. The cartridges were initially preconditioned with $5 \mathrm{ml}$ of methanol followed by equilibration with $5 \mathrm{ml}$ ultra-high purity water. Both conditioning and equilibration solvents were percolated through the cartridge at $1 \mathrm{ml} \mathrm{min}^{-1}$. The water samples $(500 \mathrm{ml})$ were then loaded at $15 \mathrm{ml} \mathrm{min}^{-1}$. The cartridges were then rinsed with $2 \mathrm{ml}$ of ultra-high purity water at $5 \mathrm{ml} \mathrm{min}{ }^{-1}$ followed by drying with a stream of nitrogen gas at $1 \mathrm{ml} \mathrm{min}{ }^{-1}$ for $5 \mathrm{~min}$. Finally, the analytes were eluted with $8 \mathrm{ml}$ methanol at $1 \mathrm{ml} \mathrm{min}{ }^{-1}$. The eluent was evaporated to near dryness with a slow stream of nitrogen gas and then reconstituted with $1 \mathrm{ml}$ of $0.1 \%$ formic acid in methanol and taken to the UHPLC-QTOF-MS for analysis.

\section{Liquid Chromatography-Mass Spectrometry Analysis Liquid Chromatography-Mass Spectrometry Conditions}

The Dionex Ultimate 3000 UHPLC system from Thermo Scientific (Sunnyvale, California, United States) coupled with a 
quadrupole time-of-flight mass spectrometric detector from Bruker Daltonics (Bremen, Germany) (UHPLC-QTOF-MS) was used for identification of the targeted antibiotics. Separation of compounds ( $5 \mu \mathrm{L}$ injection) was achieved on a Luna ${ }^{\circledR}$ Omega C18 column $(50 \mathrm{~mm} \times 4.6 \mathrm{~mm} \times 3 \mu \mathrm{m})$ from Phenomenex (California, United States). The mass spectrometric detection was operated in the positive electrospray ionization mode. Elution was done in gradient mode using a mobile phase consisting of $0.1 \%(\mathrm{v} / \mathrm{v})$ formic acid in water (solvent $\mathrm{A}$ ) and $0.1 \%$ $(\mathrm{v} / \mathrm{v})$ formic acid in acetonitrile (solvent $\mathrm{B}$ ). The elution program started with $5 \%$ solvent $\mathrm{B}$ in the first $0.5 \mathrm{~min}$, ramped continuously to $90 \%$ in the next $22 \mathrm{~min}$, held for $1 \mathrm{~min}$ and finally re-equilibrated to initial conditions (5\% solvent B) over $5 \mathrm{~min}$ for a total run time of $27.5 \mathrm{~min}$. Data acquisition was performed using Data Analysis 4.3 software from Bruker Daltonics (Bremen, Germany).

\section{Targeted Antibiotics}

The targeted antibiotics consisted of 47 parent compounds, three known acetyl-derivatives of sulfonamides and two of the hydroxy-derivatives of metronidazole and trimethoprim. The screened antibiotics and antibiotic derivatives cover those that have been detected previously in South Africa and Africa as a whole, antibiotics detected in other developing countries as well as those detected and listed as priority antibiotics in the western water systems. Of these antibiotics, 12 are not registered on the official pharmaceutical regulatory authority, the South African Health Products Regulatory Authority (https://www.sahpra.org. $\mathrm{za} /$ registered-health-products/). The investigated number of antibiotics correlates with the targeted numbers investigated across the globe including 53 antibiotics across Europe (Cyprus, Finland, Germany, Ireland, Norway, Portugal and Spain) (Rodriguez-mozaz et al., 2020), 50 antibiotics in China (Zhou et al., 2013) and 52 antibiotics studied in the Netherlands (Sabri et al., 2020) which indicates the relevance of the current study.

\section{Compound Identification}

The mass spectrometry data was converted to mzXML and then pre-assessed with MZmine 2.53 (Pluskal et al., 2010). The procedure comprised of peak detection, subtraction of isotopes, correction of retention time, peak matching, and peak filling. Peak detection was executed in three phrase such as 1) mass detection with noise value $=15,000$ and an auto retention time range; 2) chromatogram builder with minimum time span $=0.1 \mathrm{~min}$, minimum height $=15,000$ and $\mathrm{m} / \mathrm{z}$ tolerance $=0.005 \mathrm{Da}$ or $20 \mathrm{ppm} ; 3$ ) deconvolution with peak width $=0.11-2 \mathrm{~min}$, noise $=20,000$. Isotopes were removed using the isotopic peak grouper with $\mathrm{m} / \mathrm{z}$ tolerance $=0.005 \mathrm{Da}$ or $10 \mathrm{ppm}$, retention time tolerance $=3.5 \mathrm{~min}$ and minimum standard intensity $=20,000$. Then, a filter was used to keep only those ions with at least 2 peaks in their isotope pattern. The retention time was amended with $\mathrm{m} / \mathrm{z}$ tolerance $=0.005 \mathrm{Da}$ or $20 \mathrm{ppm}$, retention time tolerance $=0.5 \mathrm{~min}$ and minimum standard intensity $=20,000$. Peak matching among samples was achieved using the RANSAC aligner with $\mathrm{m} / \mathrm{z}$ tolerance = $0.005 \mathrm{Da}$ or $10 \mathrm{ppm}$, retention time tolerance before and after correction $=3.5$ and 2 min respectively. RANSAC iterations and the threshold were set at 10,000 and $65 \%$, respectively.

\section{Health Risk Assessment}

Health risk assessment was done based on the ratio of the maximum environmental concentration (MEC) to the predicted non-effect concentration (PNEC). The PNECresistance and PNEC-ecotoxicity that cater for antibiotic resistance and ecotoxicity, respectively were considered in predicting potential impact of the quantified antibiotics (Tell et al., 2019). The PNEC-resistance data represents values that would result in antibiotic resistance based on the lowest minimal inhibitory concentrations (MICs) (Bengtsson-Palme and Larsson, 2016). The lowest MIC values presented in the EUCAST database are for up to 25 families of clinical and environmental bacteria (https://mic.eucast.org/search/). The PNEC-ecotoxicity values were adapted from Bengtsson-Palme and Larsson 2016 and confirmed from the original source, the Farmaceutiska Specialiteter i Sverige (FASS) (https://www.fass.se/ $\mathrm{LIF} /$ startpage) which is a Swedish pharmaceutical data base. The FASS data base does not have PNEC values for deregistered drugs. Both the EUCAST and the FASS databases were accessed between 25th March and sixth May 2021. The lowest value between the two parameters (PNEC-resistance and PNECecotoxicity) and the highest measured environmental concentration of the antibiotic were therefore used as worstcase scenarios in estimation of the Risk Quotient (HQ) using Eq. 1. The criterion for $R Q$ values is as follows; $R Q \leq 0.1$ (environmental risk is low), $0.1<\mathrm{RQ} \leq 1$ (environmental risk is moderate) and RQ $>1$ (environmental risk is high) (Rodriguezmozaz et al., 2020).

$$
R Q=M E C / P N E C
$$

where $R Q$ is the Risk Quotient, $M E C$ is the maximum environmental concentration and PNEC is the predicted noneffect concentration.

\section{RESULTS AND DISCUSSION}

\section{Method Validation}

Matrix effects are known to affect instrument response towards target analytes (Rivera-Jaimes et al., 2018). In the current study, all the analytes experienced signal suppression effects with the flumequine most affected while the sulfonamides (sulfamethizole, sulfamethazine, sulfamethoxazole) and the diaminopyrimidine (trimethoprim) were less affected with signal suppression ranging between 4 and 19\% (Table 1). However, of the sulfonamides, only sulfamethizole was least affected recording $4 \%$ suppression in signal response which was within the $\pm 15 \%$ range considered acceptable in this study. In this regard, matrix-matched calibrations were performed for all the targeted antibiotics. For those calibration curves where the standard deviation of the model was greater than the $y$-intercept, the origin (point $0 ; 0$ ) was set as the intercept. This was done for the calibration for trimethoprim. The linearity of the models was good ranging 
TABLE 1 | Method validation parameters.

\begin{tabular}{|c|c|c|c|c|c|c|c|}
\hline Antibiotic & Class & Calibration Equation & $\mathbf{R}^{2}$ & ILOD $\left(\mu \mathrm{g} \mathrm{L}^{-1}\right)$ & $M D L\left(\mu g L^{-1}\right)$ & Recovery ( $\% \pm \%$ RSD) & Matrix effects \% \\
\hline Sulfamethizole & Sulfonamide & $y=1986.2 x-72722$ & 0.984 & 26.9 & 0.0539 & $89 \pm 4.5$ & -4 \\
\hline Sulfamethazine & Sulfonamide & $y=2011.3 x-109318$ & 0.984 & 39.2 & 0.0784 & $97 \pm 12$ & -19 \\
\hline Sulfamethoxazole & Sulfonamide & $y=2380.9 x-68979$ & 0.993 & 25.0 & 0.0500 & $94 \pm 13$ & -18 \\
\hline Trimethoprim & Diaminopyrimidine & $y=3126.9 x$ & 0.997 & 12.4 & 0.0247 & $94 \pm 11$ & -17 \\
\hline Flumequine & Fluoroquinolone & $y=3404.1 x-378004$ & 0.984 & 16.8 & 0.0335 & $96 \pm 9.2$ & -47 \\
\hline
\end{tabular}

ILOD, instrument limit of detection; MDL, method detection limit.

between 0.984 and 0.997 . The method validation parameters are given in Table 1. Recoveries were recorded as averages for three spiking levels of 1,10 and $100 \mu \mathrm{g} \mathrm{L}^{-1}$ which equated to about 20 , 200 and 2,000 times the limit of quantitation of most analytes, respectively. The recovery values were within the acceptable range (89-97\%) and also had good repeatability of RSD $\leq 12 \%$.

\section{Detection and Identification of Antibiotics}

There were 15 antibiotics detected in the stream carrying wastewater effluents and dumpsite leachates of which 5 compounds (3 sulfonamides, 1 fluoroquinolone and 1 diaminopyrimidine) were quantified (Table 2). These numbers are comparable with other studies that did extensive screening elsewhere. For example, comprehensive monitoring of 53 antibiotics across Europe (Cyprus, Finland, Germany, Ireland, Norway, Portugal and Spain) in 2015/6 led to detection of 17 antibiotics (Rodriguez-mozaz et al., 2020), in China there were 17 antibiotics detected in WWTP effluents from a list of 50 targeted antibiotics (Zhou et al., 2013) while a study in the Netherlands investigated 52 antibiotics (Sabri et al., 2020). The quantified sulfonamides (sulfamethizole, sulfamethazine, sulfamethoxazole) in the current study ranged from not detected to $0.133 \mu \mathrm{g} \mathrm{L}^{-1}$, the fluoroquinolone (flumequine) from 0.222 to $0.686 \mu \mathrm{g} \mathrm{L}^{-1}$ while the diaminopyrimidine, trimethoprim was up to $0.0618 \mu \mathrm{g} \mathrm{L} \mathrm{L}^{-1}$. Most of the antibiotics were only detected at the point of exit of effluents into the stream (Site 1) which was indicative of either dilution effects or possibly degradation by environmental conditions. Antibiotic reduction downstream has been reported elsewhere (Zhang et al., 2013). Wastewater dilution factors for South Africa are predicted at 10-40 (Keller et al., 2014).

While there are no guidelines on the release of antibiotics at the point of exit of effluents from wastewater treatment works, a previous study on species sensitivity and antimicrobial resistance has recommended $100 \mathrm{ng} \mathrm{L}^{-1}$ as the maximum concentration for any antibiotic (Le Page et al., 2017). The concentrations reported for the selected antibiotics in the current study show that only trimethoprim and sulfamethoxazole were within the suggested value (Table 2). The implication is that the wastewater effluents and dumpsite leachates are releasing elevated concentrations of antibiotics into the surface water. Since the concentration of the other antibiotics detected in the effluents was not ascertained, there is a likelihood that more of these were also above the $100 \mathrm{ng}$ $\mathrm{L}^{-1}$ set point. It should be noted that $100 \mathrm{ng} \mathrm{L}^{-1}$ set value is less than the PNEC values (Section 3.4) for most antibiotics detected in the current study except for Penicillin $\mathrm{V}$ whose PNEC value is $64 \mathrm{ng} \mathrm{L}^{-1}$.
Sulfamethoxazole and trimethoprim are the frequently detected antibiotics in Africa and Asia (Faleye et al., 2018; Madikizela et al., 2020; Wang et al., 2020). Sulfamethoxazole has been detected in African wastewater effluents ranging between 0.15 and $10 \mu \mathrm{g} \mathrm{L}^{-1}$ (Hendricks and Pool, 2012; K'oreje et al., 2016; Ngumba et al., 2016; Mhuka et al., 2020). In the current study, the sulfamethoxazole concentration was $0.0868 \mu \mathrm{g} \mathrm{L}^{-1}$ which is lower than any reported concentration in Africa. Trimethoprim and flumequine in the current study also had lower concentrations compared to wastewater effluents reported in other African studies (Tahrani et al., 2017; AbouElwafa Abdallah et al., 2019; Mhuka et al., 2020). The wastewater effluents and the dumpsite leachates are first held in an artificial dam and release into the sampled stream mostly due to overflow. This might allow ample time for pollutants to undergo further degradation before release into the stream. While recent African reviews have observed that most environmental antibiotic concentrations are higher in Africa than anywhere in the world (Faleye et al., 2018; Madikizela et al., 2020), the reported concentrations for sulfamethoxazole $\left(0.0868 \mu \mathrm{g} \mathrm{L} \mathrm{L}^{-1}\right)$ and trimethoprim $\left(0.0618 \mu \mathrm{g} \mathrm{L}^{-1}\right)$ in the current study are comparable with those reported elsewhere. For example, in one study in China their concentrations in WWTP effluents were up to 0.106 and $0.064 \mu \mathrm{g} \mathrm{L}^{-1}$, respectively (Zhou et al., 2013) while in Europe they ranged from not detected to $0.123 \mu \mathrm{g} \mathrm{L}$ (sulfamethoxazole) and $0.0152-0.190 \mu \mathrm{g} \mathrm{L}^{-1}$ (trimethoprim) (Rodriguez-mozaz et al., 2020). Sulfamethazine is lower than that reported in effluents from a Japanese WWTP (Behera et al., 2011).

Our study also included 12 unregistered antibiotics (flumequine, sarafloxacin, ceftazidine, difloxacin, sparfloxacin, oleandomycin, oxacillin, oxolinic acid, sulfamerazine, sulfamethoxypyridazine, sulfanilamide, sulfapyridine). Antibiotic consumption in South Africa is regulated by the South African Health Products Regulatory Authority website; https://www.sahpra.org.za/registeredhealth-products/. Interestingly, flumequine and oxacillin were detected in the stream which indicates a possibility of illegal prescriptions or entrance into the country carried by tourists. The concentration of flumequine was almost constant in all sampling sites ranging between 0.222 and 0 . $686 \mu \mathrm{g} \mathrm{L}^{-1}$. Flumequine is a broad-spectrum antibiotic and its detection in surface water maybe from veterinary applications rather than human consumption. Previous studies have shown that flumequine is persistent in the environment (Jara et al., 2021). 
TABLE 2 | Detected antibiotics and health risk assessment.

\begin{tabular}{|c|c|c|c|c|c|c|c|c|c|c|c|c|}
\hline \multirow[t]{2}{*}{ Antibiotic } & \multirow[t]{2}{*}{ Class } & \multirow{2}{*}{$\begin{array}{c}\text { PNEC- } \\
\text { resistance } \\
(\mu \mathrm{g} \\
\left.\mathrm{L}^{-1}\right)\end{array}$} & \multirow{2}{*}{$\begin{array}{c}\text { PNEC- } \\
\text { ecotoxicity } \\
(\mu \mathrm{g} \\
\left.\mathrm{L}^{-1}\right)\end{array}$} & \multirow{2}{*}{$\begin{array}{c}\text { Lowest } \\
\text { PNEC } \\
\left(\mu \mathrm{g} \mathrm{L}^{-1}\right)\end{array}$} & \multirow[t]{2}{*}{$\mathbf{R Q}$} & \multicolumn{7}{|c|}{ Concentration $\left(\mu \mathrm{g} \mathrm{L}^{-1}\right)$} \\
\hline & & & & & & Site 1 & $\begin{array}{c}\text { Site } \\
2\end{array}$ & $\begin{array}{c}\text { Site } \\
3\end{array}$ & $\begin{array}{c}\text { Site } \\
4\end{array}$ & $\begin{array}{l}\text { Site } \\
5\end{array}$ & $\begin{array}{l}\text { Site } \\
6\end{array}$ & $\begin{array}{c}\text { Site } \\
7\end{array}$ \\
\hline Trimethoprim & Diaminopyrimidine & 0.5 & 56 & 0.5 & 0.12 & $0.0618^{a}$ & n.d & n.d & n.d & n.d & n.d & n.d \\
\hline Sulfamethoxazole & sulfonamide & 16 & 0.59 & 0.59 & 0.15 & $0.0868^{a}$ & n.d & n.d & n.d & n.d & n.d & n.d \\
\hline Sulfamethizole & Sulfonamide & - & - & - & - & 0.111 & n.d & n.d & n.d & n.d & n.d & n.d \\
\hline Sulfamethazine & Sulfonamide & - & - & - & - & 0.133 & n.d & n.d & n.d & n.d & n.d & n.d \\
\hline Flumequine & Fluoroquinolone & 0.25 & - & 0.25 & 2.7 & 0.222 & 0.258 & 0.231 & 0.686 & 0.222 & 0.227 & 0.235 \\
\hline Erythromycin & Macrolide & 1 & 0.103 & - & - & $\checkmark$ & n.d & n.d & n.d & n.d & n.d & n.d \\
\hline Ofloxacin & Fluoroquinolone & 0.5 & 10 & - & - & $\checkmark$ & n.d & n.d & n.d & n.d & n.d & n.d \\
\hline Ampicillin & Penicillin & 0.25 & - & - & - & $\checkmark$ & n.d & n.d & n.d & n.d & n.d & n.d \\
\hline Penicillin V & Penicillin & 0.064 & - & - & - & $\checkmark$ & n.d & n.d & n.d & n.d & n.d & n.d \\
\hline Sulfathiazole & Sulfonamide & - & - & - & - & $\checkmark$ & n.d & n.d & n.d & n.d & n.d & n.d \\
\hline Penicillin G & Penicillin & - & - & - & - & $\checkmark$ & n.d & n.d & n.d & n.d & n.d & n.d \\
\hline Oxacillin & Penicillin & - & - & - & - & $\checkmark$ & $\checkmark$ & n.d & $\checkmark$ & n.d & n.d & n.d \\
\hline Sulfadiazine & Sulfonamide & - & - & - & - & $\checkmark$ & $\checkmark$ & n.d & $\checkmark$ & $\checkmark$ & n.d & $\checkmark$ \\
\hline Azithromycin & Macrolide & - & - & - & - & n.d & n.d & n.d & $\checkmark$ & n.d & n.d & n.d \\
\hline Roxithromycin & Macrolide & - & - & - & - & n.d & n.d & n.d & $\checkmark$ & $\checkmark$ & $\checkmark$ & n.d \\
\hline Ciprofloxacin & Fluoroquinolone & - & - & - & - & n.d & n.d & n.d & n.d & n.d & n.d & n.d \\
\hline Clarithromycin & Macrolide & - & - & - & - & n.d & n.d & n.d & n.d & n.d & n.d & n.d \\
\hline Enrofloxacin & Fluoroquinolone & - & - & - & - & n.d & n.d & n.d & n.d & n.d & n.d & n.d \\
\hline Sarafloxacin & Fluoroquinolone & - & - & - & - & n.d & n.d & n.d & n.d & n.d & n.d & n.d \\
\hline Chloramphenicol & Amphenicol & - & - & - & - & n.d & n.d & n.d & n.d & n.d & n.d & n.d \\
\hline Thiamphenicol & Amphenicol & - & - & - & - & n.d & n.d & n.d & n.d & n.d & n.d & n.d \\
\hline Florfenicol & Amphenicol & - & - & - & - & n.d & n.d & n.d & n.d & n.d & n.d & n.d \\
\hline Cefaclor & Cephalosporin & - & - & - & - & n.d & n.d & n.d & n.d & n.d & n.d & n.d \\
\hline Cefadroxil & Cephalosporin & - & - & - & - & n.d & n.d & n.d & n.d & n.d & n.d & n.d \\
\hline Ceftazidine & Cephalosporin & - & - & - & - & n.d & n.d & n.d & n.d & n.d & n.d & n.d \\
\hline Cefuroxime & Cephalosporin & - & - & - & - & n.d & n.d & n.d & n.d & n.d & n.d & n.d \\
\hline Cephalexin & Cephalosporin & - & - & - & - & n.d & n.d & n.d & n.d & n.d & n.d & n.d \\
\hline Cephradine & Cephalosporin & - & - & - & - & n.d & n.d & n.d & n.d & n.d & n.d & n.d \\
\hline $\begin{array}{l}\text { Trimethoprim, } \\
\text { a-hydroxy- }\end{array}$ & Diaminopyrimidine & - & - & - & - & n.d & n.d & n.d & n.d & n.d & n.d & n.d \\
\hline Difloxacin & Fluoroquinolone & - & - & - & - & n.d & n.d & n.d & n.d & n.d & n.d & n.d \\
\hline Lomefloxacin & Fluoroquinolone & - & - & - & - & n.d & n.d & n.d & n.d & n.d & n.d & n.d \\
\hline Sparfloxacin & Fluoroquinolone & - & - & - & - & n.d & n.d & n.d & n.d & n.d & n.d & n.d \\
\hline Clindamycin & Lincomycin & - & - & - & - & n.d & n.d & n.d & n.d & n.d & n.d & n.d \\
\hline Oleandomycin & Macrolide & - & - & - & - & n.d & n.d & n.d & n.d & n.d & n.d & n.d \\
\hline Metronidazol, hydroxy- & Nitroimidazole & - & - & - & - & n.d & n.d & n.d & n.d & n.d & n.d & n.d \\
\hline Metronidazole & Nitroimidazole & - & - & - & - & n.d & n.d & n.d & n.d & n.d & n.d & n.d \\
\hline Amoxicillin & Penicillin & - & - & - & - & n.d & n.d & n.d & n.d & n.d & n.d & n.d \\
\hline Nalidixic acid & Quinolone & - & - & - & - & n.d & n.d & n.d & n.d & n.d & n.d & n.d \\
\hline Oxolinic acid & Quinolone & - & - & - & - & n.d & n.d & n.d & n.d & n.d & n.d & n.d \\
\hline Sulfachloropyridazine & Sulfonamide & - & - & - & - & n.d & n.d & n.d & n.d & n.d & n.d & n.d \\
\hline Sulfadiazine, N-acetyl- & Sulfonamide & - & - & - & - & n.d & n.d & n.d & n.d & n.d & n.d & n.d \\
\hline Sulfadimethoxine & Sulfonamide & - & - & - & - & n.d & n.d & n.d & n.d & n.d & n.d & n.d \\
\hline Sulfamerazine & Sulfonamide & - & - & - & - & n.d & n.d & n.d & n.d & n.d & n.d & n.d \\
\hline Sulfamethazine, N-acetyl & Sulfonamide & - & - & - & - & n.d & n.d & n.d & n.d & n.d & n.d & n.d \\
\hline Sulfamethiazole & Sulfonamide & - & - & - & - & n.d & n.d & n.d & n.d & n.d & n.d & n.d \\
\hline $\begin{array}{l}\text { Sulfamethoxazole, } \\
\text { N-acetyl- }\end{array}$ & Sulfonamide & - & - & - & - & n.d & n.d & n.d & n.d & n.d & n.d & n.d \\
\hline Sulfamethoxypyridazine & Sulfonamide & - & - & - & - & n.d & n.d & n.d & n.d & n.d & n.d & n.d \\
\hline Sulfanilamide & Sulfonamide & - & - & - & - & n.d & n.d & n.d & n.d & n.d & n.d & n.d \\
\hline Sulfapyridine & Sulfonamide & - & - & - & - & n.d & n.d & n.d & n.d & n.d & n.d & n.d \\
\hline Sulfisoxazole & Sulfonamide & - & - & - & - & n.d & n.d & n.d & n.d & n.d & n.d & n.d \\
\hline Oxytetracycline & Tetracycline & - & - & - & - & n.d & n.d & n.d & n.d & n.d & n.d & n.d \\
\hline Tetracycline & Tetracycline & - & - & - & - & n.d & n.d & n.d & n.d & n.d & n.d & n.d \\
\hline
\end{tabular}

n.d, not detected; PNEC, predicted non-effect concentration; RQ, Risk Quotient.

${ }^{a}$ Compound was detected but its value was below the method quantitation limit. These values were used in health risk assessment predictions.

On a positive note, none of the derivatives of selected antibiotics were detected in the stream. The detection of the antibiotics downstream was limited with most being undetected in sites before the stream-river confluence. An exception was observed for the stable flumequine. A spike in the concentration of 5 antibiotics (flumequine, oxacillin, sulfadiazine, azithromycin, 
roxithromycin) was also observed at sampling site 4 where the study stream meets another stream from a small WWTP (Figure 1). Of these, azithromycin, roxithromycin were first detected at this point implying that their source was the small WWTP. In addition, roxithromycin and sulfadiazine already existed in the Klip River before receiving the effluents (Site 5) implying another source upstream. The Klip River passes through a dense township where proper sanitation is limited.

\section{Health Risk Assessment}

The health risk assessment data is summarized in Table 2. Of the 5 quantified antibiotics, only three (trimethoprim, sulfamethoxazole and flumequine) had PNEC values. Their calculated RQ values were $0.12,0.15$ and 2.7 , respectively. These estimations imply that there is moderate risk for the environment due to trimethoprim and sulfamethoxazole while the risk is high for flumequine. This raises further concern regarding the other antibiotics that were detected but not quantified. Across Europe, for example, most of the reported concentrations of antibiotics are within PNECs (Carvalho and Santos, 2016) while only a few such as trimethoprim, azithromycin, clarithromycin and amoxicillin and erythromycin have been identified as antibiotics of interest with RQ $\geq 0.1$ (Riva et al., 2019; Sörengård et al., 2019; Rodriguez-mozaz et al., 2020). Elsewhere in Asia, some studies have reported very high risks due to antibiotics notably sulfamethoxazole with an RQ value of 31.3 in surface water (Li et al., 2012; Hu et al., 2018).

\section{IMPLICATIONS OF THE STUDY}

More studies are needed to identify the antibiotics present in surface water systems of South Africa and Africa as a whole. This should form a basis for proposal of focused prospective regulatory frameworks relevant to Africa. The high concentrations of antibiotics in surface water in Africa is worrying since it only takes a once-off transfer of an antibiotic resistant gene from the environment into a human being (Larsson, 2014). Quite a large number of Africa's population has suppressed immune systems due to various factors related to pandemics, hunger and general lack of health care resources (Faleye et al., 2018), for example, Africa is home to over 36 million people living with HIV (Ncube et al., 2018).

In this regard, there is need to refine the PNEC estimates based on the types of bacteria prevalent in different geographical regions and relate to the global antibiotic consumption trends. The antibioticspecific approach has been echoed by Tell et al., 2019 (Tell et al., 2019). For example, an European study covering Cyprus, Finland, Germany, Ireland, Norway, Portugal, and Spain identified only three compounds (ciprofloxacin, azithromycin and cefalexin) from a list of 50 antibiotics to be considered as markers of antibiotic pollution (Rodriguez-mozaz et al., 2020). As stated earlier, sulfamethoxazole and trimethoprim are more prevalent in Africa (Faleye et al., 2018; Madikizela et al., 2020) while in Asia, studies have observed higher concentrations for various antibiotics mainly fluoroquinolones (Jia et al., 2012; Jiang et al., 2014; Shi et al., 2020; Zafar et al., 2021). These variations are an indication of the need of more region-specific studies. Currently, there are only five antibiotics (ciprofloxacin, azithromycin, erythromycin and clarithromycin, and amoxicillin) listed under the Water Framework Directive (WFD) watch list for European Union countries priority (Directive 2018/840/EC, 2018).

The considerations of both PNEC-resistance and PNECecotoxicity in the current study allow for assessment of the true extent of environmental impact of antibiotics. Other studies have done this approach (Rodriguez-mozaz et al., 2020) while most of the studies only use the PNEC-ecotoxicity in their estimation of HQs. A paradigm shift is therefore needed in which both risk parameters are considered for precision environmental risk predictions.

Since the number of studies on multi-residue screening is still limited in Africa's surface water (Harrabi et al., 2018; Rimayi et al., 2019; Mhuka et al., 2020), more research is needed. The identification of unregistered antibiotics is also a cause of concern. The situation is worsened by lack of stringent protocols on pharmaceutical control to ensure that unregistered antibiotics do not enter the country and get prescribed to the population illegally. We, therefore, project that quite a large number of studies on multi-residue screening of pharmaceuticals will be available in the near future using more sensitive instrumentation thus creating a more comprehensive database that can be used as a starting point for focused African regulatory frameworks.

Internationally, more studies on clinical and environmental bacterial resistance data are needed including increasing the number of bacterial taxa used in studies. Different families of bacteria respond differently, and more focused studies are required. The risk assessment data available in literature is biased towards the Cyanobacteriaceae family. This family of bacteria is known to be highly sensitive to antibiotic exposure yet it is also resistant to heat treatment such as cooking (Le Page et al., 2017). We, therefore, predict that the discussion of our results based on data on bacteria found in the cooler western conditions may underestimate the true risk to the bacteria found in a typical South African surface water. Furthermore, the authors of the resistance data predictions referenced in this study do appreciate that their values may be biased due to the fact that only a few bacterial taxa is mentioned in the FASS database (Bengtsson-Palme and Larsson, 2016). The bacteria existing in our study stream and the receiving river is currently unknown. This offers challenges and more inclusive studies are required to ascertain the bacterial families present and determine their sensitivity towards the detected antibiotics.

\section{CONCLUSION}

The current study has detected 15 antibiotics belonging to different classes from 52 targeted compounds that were screened in a stream receiving wastewater effluents and municipal dumpsite leachates. The study is the first to extensively and selectively screen antibiotics in environmental aqueous samples in South Africa with the aim of setting a strong basis for further studies. Some of the detected antibiotics are not sanctioned in South Africa while most of the quantified ones were above their predicted non-effect concentrations in the environment. The study also detected unsanctioned antibiotics which reflects a common practice in 
Africa where there are no protocols to ensure the population only consumes permitted antibiotics. The current study is expected to result in more studies being done which in turn will contribute towards drafting of environmental risk assessment legislation, guidelines, and directives specific for South Africa and Africa at large.

\section{DATA AVAILABILITY STATEMENT}

The original contributions presented in the study are included in the article/supplementary material, further inquiries can be directed to the corresponding author.

\section{REFERENCES}

Abou-Elwafa Abdallah, M., Nguyen, K.-H., Ebele, A. J., Atia, N. N., Ali, H. R. H., and Harrad, S. (2019). A Single Run, Rapid Polarity Switching Method for Determination of 30 Pharmaceuticals and Personal Care Products in Waste Water Using Q-Exactive Orbitrap High Resolution Accurate Mass Spectrometry. J. Chromatogr. A 1588, 68-76. doi:10.1016/j.chroma.2018.12.033

Archer, E., Wolfaardt, G. M., and Van Wyk, J. H. (2017). Review: Pharmaceutical and Personal Care Products (PPCPs) as Endocrine Disrupting Contaminants (EDCs) in South African Surface Waters. Wsa 43, 684-706. doi:10.4314/ wsa.v43i4.16

Behera, S. K., Kim, H. W., Oh, J.-E., and Park, H.-S. (2011). Occurrence and Removal of Antibiotics, Hormones and Several Other Pharmaceuticals in Wastewater Treatment Plants of the Largest Industrial City of Korea. Sci. Total Environ. 409, 4351-4360. doi:10.1016/j.scitotenv.2011.07.015

Bengtsson-Palme, J., and Larsson, D. G. J. (2016). Concentrations of Antibiotics Predicted to Select for Resistant Bacteria: Proposed Limits for Environmental Regulation. Environ. Int. 86, 140-149. doi:10.1016/j.envint.2015.10.015

Carvalho, I. T., and Santos, L. (2016). Antibiotics in the Aquatic Environments: A Review of the European Scenario. Environ. Int. 94, 736-757. doi:10.1016/ j.envint.2016.06.025

Directive 2018/840/EC (2018). COMMISSION IMPLEMENTING DECISION (EU) 2018/840 of 5 June 2018 Establishing a Watch List of Substances for Union-wide Monitoring in the Field of Water Policy Pursuant to Directive 2008/105/EC of the European Parliament and of the Council and Repealing Comm. Off. J. Eur. Union L. 141, 9-12.

Ebele, A. J., Abou-Elwafa Abdallah, M., and Harrad, S. (2017). Pharmaceuticals and Personal Care Products (PPCPs) in the Freshwater Aquatic Environment. Emerging Contaminants 3, 1-16. doi:10.1016/j.emcon.2016.12.004

Elijah Ngumba, E., Anthony Gachanja, A., James Nyirenda, J., Johanna Maldonado, J., and Tuula Tuhkanen, T. (2020). Occurrence of Antibiotics and Antiretroviral Drugs in Source-Separated Urine, Groundwater, Surface Water and Wastewater in the Peri-Urban Area of Chunga in Lusaka, Zambia. Wsa 46, 278-284. doi:10.17159/wsa/2020.v46.i2.8243

Faleye, A. C., Adegoke, A. A., Ramluckan, K., Bux, F., and Stenström, T. A. (2018). Antibiotic Residue in the Aquatic Environment: Status in Africa. Open Chem. 16, 890-903. doi:10.1515/chem-2018-0099

Faleye, A. C., Adegoke, A. A., Ramluckan, K., Fick, J., Bux, F., and Stenström, T. A. (2019). Concentration and Reduction of Antibiotic Residues in Selected Wastewater Treatment Plants and Receiving Waterbodies in Durban, South Africa. Sci. Total Environ. 678, 10-20. doi:10.1016/j.scitotenv.2019.04.410

Fekadu, S., Alemayehu, E., Dewil, R., and Van der Bruggen, B. (2019). Pharmaceuticals in Freshwater Aquatic Environments: A Comparison of the African and European challenge. Sci. Total Environ. 654, 324-337. doi:10.1016/ j.scitotenv.2018.11.072

Furlong, E. T., Batt, A. L., Glassmeyer, S. T., Noriega, M. C., Kolpin, D. W., Mash, H., et al. (2017). Nationwide Reconnaissance of Contaminants of Emerging Concern in Source and Treated Drinking Waters of the United States: Pharmaceuticals. Sci. Total Environ. 579, 1629-1642. doi:10.1016/ j.scitotenv.2016.03.128

\section{AUTHOR CONTRIBUTIONS}

SN: conceptualization, methodology, writing and editing. YN: conceptualization, methodology and editing. LC: reviewing and editing. LM: conceptualization and editing. AE: conceptualization, editing and funding.

\section{FUNDING}

This study was supported by the Volkswagen Foundation fellowship awarded to $\mathrm{AE}$ and the National Research Foundation of South Africa (Grant no. 129627) awarded to SN.

Gwenzi, W., and Chaukura, N. (2018). Organic Contaminants in African Aquatic Systems: Current Knowledge, Health Risks, and Future Research Directions. Sci. Total Environ. 619-620, 1493-1514. doi:10.1016/j.scitotenv.2017.11.121

Harrabi, M., Varela Della Giustina, S., Aloulou, F., Rodriguez-Mozaz, S., Barceló, D., and Elleuch, B. (2018). Analysis of Multiclass Antibiotic Residues in Urban Wastewater in Tunisia. Environ. Nanotechnology, Monit. Manag. 10, 163-170. doi:10.1016/j.enmm.2018.05.006

Hendricks, R., and Pool, E. J. (2012). The Effectiveness of Sewage Treatment Processes to Remove Faecal Pathogens and Antibiotic Residues. J. Environ. Sci. Health A 47, 289-297. doi:10.1080/10934529.2012.637432

Hu, Y., Yan, X., Shen, Y., Di, M., and Wang, J. (2018). Antibiotics in Surface Water and Sediments from Hanjiang River, Central China: Occurrence, Behavior and Risk Assessment. Ecotoxicology Environ. Saf. 157, 150-158. doi:10.1016/ j.ecoenv.2018.03.083

Jara, B., Tucca, F., Srain, B. M., Méjanelle, L., Aranda, M., Fernández, C., et al. (2021). Antibiotics Florfenicol and Flumequine in the Water Column and Sediments of Puyuhuapi Fjord, Chilean Patagonia. Chemosphere 275, 130029. doi:10.1016/j.chemosphere.2021.130029

Jia, A., Wan, Y., Xiao, Y., and Hu, J. (2012). Occurrence and Fate of Quinolone and Fluoroquinolone Antibiotics in a Municipal Sewage Treatment Plant. Water Res. 46, 387-394. doi:10.1016/j.watres.2011.10.055

Jiang, Y., Li, M., Guo, C., An, D., Xu, J., Zhang, Y., et al. (2014). Distribution and Ecological Risk of Antibiotics in a Typical Effluent-Receiving River (Wangyang River) in north China. Chemosphere 112, 267-274. doi:10.1016/ j.chemosphere.2014.04.075

K'oreje, K. O., Vergeynst, L., Ombaka, D., De Wispelaere, P., Okoth, M., Van Langenhove, H., et al. (2016). Occurrence Patterns of Pharmaceutical Residues in Wastewater, Surface Water and Groundwater of Nairobi and Kisumu City, Kenya. Chemosphere 149, 238-244. doi:10.1016/j.chemosphere.2016.01.095

Keller, V. D. J., Williams, R. J., Lofthouse, C., and Johnson, A. C. (2014). Worldwide Estimation of River Concentrations of Any Chemical Originating from Sewagetreatment Plants Using Dilution Factors. Environ. Toxicol. Chem. 33, 447-452. doi:10.1002/etc.2441

Kimosop, S. J., Getenga, Z. M., Orata, F., Okello, V. A., and Cheruiyot, J. K. (2016). Residue Levels and Discharge Loads of Antibiotics in Wastewater Treatment Plants (WWTPs), Hospital Lagoons, and Rivers within Lake Victoria Basin, Kenya. Environ. Monit. Assess. 188. doi:10.1007/s10661-016-5534-6

Larsson, D. G. J. (2014). Antibiotics in the Environment. Upsala J. Med. Sci. 119, 108-112. doi:10.3109/03009734.2014.896438

Le Page, G., Gunnarsson, L., Snape, J., and Tyler, C. R. (2017). Integrating Human and Environmental Health in Antibiotic Risk Assessment: A Critical Analysis of protection Goals, Species Sensitivity and Antimicrobial Resistance. Environ. Int. 109, 155-169. doi:10.1016/j.envint.2017.09.013

Lee, D., and Choi, K. (2019). Comparison of Regulatory Frameworks of Environmental Risk Assessments for Human Pharmaceuticals in EU, USA, and Canada. Sci. Total Environ. 671, 1026-1035. doi:10.1016/ j.scitotenv.2019.03.372

Li, W., Shi, Y., Gao, L., Liu, J., and Cai, Y. (2012). Occurrence of Antibiotics in Water, Sediments, Aquatic Plants, and Animals from Baiyangdian Lake in North China. Chemosphere 89, 1307-1315. doi:10.1016/ j.chemosphere.2012.05.079 
Liu, J.-L., and Wong, M.-H. (2013). Pharmaceuticals and Personal Care Products (PPCPs): A Review on Environmental Contamination in China. Environ. Int. 59, 208-224. doi:10.1016/j.envint.2013.06.012

Madikizela, L. M., Ncube, S., and Chimuka, L. (2020). Analysis, Occurrence and Removal of Pharmaceuticals in African Water Resources: A Current Status. J. Environ. Manage. 253, 109741. doi:10.1016/ j.jenvman.2019.109741

Madikizela, L. M., and Ncube, S. (2021). Occurrence and Ecotoxicological Risk Assessment of Non-steroidal Anti-inflammatory Drugs in South African Aquatic Environment: What Is Known and the Missing Information?. Chemosphere 280, 130688. doi:10.1016/j.chemosphere.2021.130688

Madikizela, L. M., Tavengwa, N. T., and Chimuka, L. (2017). Status of Pharmaceuticals in African Water Bodies: Occurrence, Removal and Analytical Methods. J. Environ. Manage. 193, 211-220. doi:10.1016/ j.jenvman.2017.02.022

Mashile, G. P., Mpupa, A., and Nomngongo, P. N. (2021). Magnetic Mesoporous Carbon/ $\beta$-Cyclodextrin-Chitosan Nanocomposite for Extraction and Preconcentration of Multi-Class Emerging Contaminant Residues in Environmental Samples. Nanomaterials 11, 540. doi:10.3390/nano11020540

Mhuka, V., Dube, S., and Nindi, M. M. (2020). Occurrence of Pharmaceutical and Personal Care Products (PPCPs) in Wastewater and Receiving Waters in South Africa Using LC-Orbitrap MS. Emerging Contaminants 6, 250-258. doi:10.1016/j.emcon.2020.07.002

Michael, I., Rizzo, L., McArdell, C. S., Manaia, C. M., Merlin, C., Schwartz, T., et al. (2013). Urban Wastewater Treatment Plants as Hotspots for the Release of Antibiotics in the Environment: A Review. Water Res. 47, 957-995. doi:10.1016/j.watres.2012.11.027

Ncube, S., Madikizela, L. M., Chimuka, L., and Nindi, M. M. (2018). Environmental Fate and Ecotoxicological Effects of Antiretrovirals: A Current Global Status and Future Perspectives. Water Res. 145, 231-247. doi:10.1016/ j.watres.2018.08.017

Ngigi, A. N., Magu, M. M., and Muendo, B. M. (2020). Occurrence of Antibiotics Residues in Hospital Wastewater, Wastewater Treatment Plant, and in Surface Water in Nairobi County, Kenya. Environ. Monit. Assess. 192. doi:10.1007/ s10661-019-7952-8

Ngumba, E., Gachanja, A., and Tuhkanen, T. (2016). Occurrence of Selected Antibiotics and Antiretroviral Drugs in Nairobi River Basin, Kenya. Sci. Total Environ. 539, 206-213. doi:10.1016/j.scitotenv.2015.08.139

Offiong, N.-A. O., Inam, E. J., and Edet, J. B. (2019). Preliminary Review of Sources, Fate, Analytical Challenges and Regulatory Status of Emerging Organic Contaminants in Aquatic Environments in Selected African Countries. Chem. Africa 2, 573-585. doi:10.1007/s42250-019-00079-6

Patel, M., Kumar, R., Kishor, K., Mlsna, T., Pittman, C. U., and Mohan, D. (2019). Pharmaceuticals of Emerging Concern in Aquatic Systems: Chemistry, Occurrence, Effects, and Removal Methods. Chem. Rev. 119, 3510-3673. doi:10.1021/acs.chemrev.8b00299

Patryn, R., Jarosz, M. J., Włoszczak-Szubzda, A., Sak, J., and Pawlikowski, J. (2011). Considerations on Directive 98/8 of the European Commission - the Biocide Directive. Ann. Agric. Environ. Med. 18, 452-458.

Philip, J. M., Aravind, U. K., and Aravindakumar, C. T. (2018). Emerging Contaminants in Indian Environmental Matrices - A Review. Chemosphere 190, 307-326. doi:10.1016/j.chemosphere.2017.09.120

Pluskal, T., Castillo, S., Villar-Briones, A., and Orešič, M. (2010). MZmine 2: Modular Framework for Processing, Visualizing, and Analyzing Mass Spectrometry-Based Molecular Profile Data. BMC Bioinformatics, 11. doi:10.1186/1471-2105-11-395

Rimayi, C., Chimuka, L., Gravell, A., Fones, G. R., and Mills, G. A. (2019). Use of the Chemcatcher Passive Sampler and Time-Of-Flight Mass Spectrometry to Screen for Emerging Pollutants in Rivers in Gauteng Province of South Africa. Environ. Monit. Assess. 191, 388. doi:10.1007/s10661-019-7515-Z

Riva, F., Zuccato, E., Davoli, E., Fattore, E., and Castiglioni, S. (2019). Risk Assessment of a Mixture of Emerging Contaminants in Surface Water in a Highly Urbanized Area in Italy. J. Hazard. Mater. 361, 103-110. doi:10.1016/ j.jhazmat.2018.07.099

Rivera-Jaimes, J. A., Postigo, C., Melgoza-Alemán, R. M., Aceña, J., Barceló, D., and López de Alda, M. (2018). Study of Pharmaceuticals in Surface and Wastewater from Cuernavaca, Morelos, Mexico: Occurrence and Environmental Risk
Assessment. Sci. Total Environ. 613-614, 1263-1274. doi:10.1016/ j.scitotenv.2017.09.134

Rodriguez-mozaz, S., Vaz-moreira, I., Varela Della Giustina, S., Llorca, M., Barceló, D., Schubert, S., et al. (2020). Antibiotic Residues in Final Effluents of European Wastewater Treatment Plants and Their Impact on the Aquatic Environment. Environ. Int. 140, 105733. doi:10.1016/j.envint.2020.105733

Sabri, N. A., van Holst, S., Schmitt, H., van der Zaan, B. M., Gerritsen, H. W., Rijnaarts, H. H. M., et al. (2020). Fate of Antibiotics and Antibiotic Resistance Genes during Conventional and Additional Treatment Technologies in Wastewater Treatment Plants. Sci. Total Environ. 741, 140199. doi:10.1016/ j.scitotenv.2020.140199

Shi, Y., Liu, J., Zhuo, L., Yan, X., Cai, F., Luo, W., et al. (2020). Antibiotics in Wastewater from Multiple Sources and Surface Water of the Yangtze River in Chongqing in China. Environ. Monit. Assess. 192. doi:10.1007/s10661-020-8108-6 Sörengård, M., Campos-Pereira, H., Ullberg, M., Lai, F. Y., Golovko, O., and Ahrens, L. (2019). Mass Loads, Source Apportionment, and Risk Estimation of Organic Micropollutants from Hospital and Municipal Wastewater in Recipient Catchments. Chemosphere 234, 931-941. doi:10.1016/j.chemosphere.2019.06.041

Tahrani, L., Van Loco, J., Anthonissen, R., Verschaeve, L., Ben Mansour, H., and Reyns, T. (2017). Identification and Risk Assessment of Human and Veterinary Antibiotics in the Wastewater Treatment Plants and the Adjacent Sea in Tunisia. Water Sci. Technol. 76, 3000-3021. doi:10.2166/wst.2017.465

Tell, J., Caldwell, D. J., Häner, A., Hellstern, J., Hoeger, B., Journel, R., et al. (2019). Science-based Targets for Antibiotics in Receiving Waters from Pharmaceutical Manufacturing Operations. Integr. Environ. Assess. Manag. 15, 312-319. doi:10.1002/ieam. 4141

Tran, N. H., Reinhard, M., and Gin, K. Y.-H. (2018). Occurrence and Fate of Emerging Contaminants in Municipal Wastewater Treatment Plants from Different Geographical Regions-A Review. Water Res. 133, 182-207. doi:10.1016/j.watres.2017.12.029

Vumazonke, S., Khamanga, S. M., and Ngqwala, N. P. (2020). Detection of Pharmaceutical Residues in Surface Waters of the Eastern Cape Province. Ijerph 17, 4067. doi:10.3390/ijerph17114067

Wang, J., Chu, L., Wojnárovits, L., and Takács, E. (2020). Occurrence and Fate of Antibiotics, Antibiotic Resistant Genes (ARGs) and Antibiotic Resistant Bacteria (ARB) in Municipal Wastewater Treatment Plant: An Overview. Sci. Total Environ. 744, 140997. doi:10.1016/j.scitotenv.2020.140997

Zafar, R., Bashir, S., Nabi, D., and Arshad, M. (2021). Occurrence and Quantification of Prevalent Antibiotics in Wastewater Samples from Rawalpindi and Islamabad, Pakistan. Sci. Total Environ. 764, 142596. doi:10.1016/j.scitotenv.2020.142596

Zhang, H., Liu, P., Feng, Y., and Yang, F. (2013). Fate of Antibiotics during Wastewater Treatment and Antibiotic Distribution in the Effluent-Receiving Waters of the Yellow Sea, Northern China. Mar. Pollut. Bull. 73, 282-290. doi:10.1016/j.marpolbul.2013.05.007

Zhou, L.-J., Ying, G.-G., Liu, S., Zhao, J.-L., Yang, B., Chen, Z.-F., et al. (2013). Occurrence and Fate of Eleven Classes of Antibiotics in Two Typical Wastewater Treatment Plants in South China. Sci. Total Environ. 452-453, 365-376. doi:10.1016/j.scitotenv.2013.03.010

Conflict of Interest: The authors declare that the research was conducted in the absence of any commercial or financial relationships that could be construed as a potential conflict of interest.

Publisher's Note: All claims expressed in this article are solely those of the authors and do not necessarily represent those of their affiliated organizations, or those of the publisher, the editors and the reviewers. Any product that may be evaluated in this article, or claim that may be made by its manufacturer, is not guaranteed or endorsed by the publisher.

Copyright (c) 2021 Ncube, Nuapia, Chimuka, Madikizela and Etale. This is an openaccess article distributed under the terms of the Creative Commons Attribution License (CC BY). The use, distribution or reproduction in other forums is permitted, provided the original author(s) and the copyright owner(s) are credited and that the original publication in this journal is cited, in accordance with accepted academic practice. No use, distribution or reproduction is permitted which does not comply with these terms. 